Atmos. Chem. Phys., 10, 1689-1699, 2010

www.atmos-chem-phys.net/10/1689/2010/

(C) Author(s) 2010. This work is distributed under

the Creative Commons Attribution 3.0 License.

\title{
Recent increase in aerosol loading over the Australian arid zone
}

\author{
R. M. Mitchell, S. K. Campbell, and Y. Qin \\ Centre for Australian Weather and Climate Research, CSIRO Marine and Atmospheric Research, Canberra, ACT, Australia
}

Received: 3 September 2009 - Published in Atmos. Chem. Phys. Discuss.: 14 October 2009

Revised: 25 January 2010 - Accepted: 3 February 2010 - Published: 15 February 2010

\begin{abstract}
Collocated sun photometer and nephelometer measurements at Tinga Tingana in the Australian Outback over the decade 1997-2007 show a significant increase in aerosol loading following the onset of severe drought conditions in 2002. This increase is confined to the season of dust activity, particularly September to March. In contrast, background aerosol levels during May, June and July remained stable. The enhanced aerosol loadings during the latter 5 years of the study period can be understood as a combination of dune destabilisation through loss of ephemeral vegetation and surface crust, and the changing supply of fluvial sediments to ephemeral lakes and floodplains within the Lake Eyre Basin. Major dust outbreaks are generally highly localised, although significant dust activity was observed at Tinga Tingana on 50\% of days when a major event occurred elsewhere in the Lake Eyre Basin, suggesting frequent basinwide dust mobilisation. Combined analysis of aerosol optical depth and scattering coefficient shows weak correlation between the surface and column aerosol $\left(R^{2}=0.24\right)$. The aerosol scale height is broadly distributed with a mode typically between $2-3 \mathrm{~km}$, with clearly defined seasonal variation. Climatological analysis reveals bimodal structure in the annual cycle of aerosol optical depth, with a summer peak related to maximal dust activity, and a spring peak related to lofted fine-mode aerosol. There is evidence for an increase in near-surface aerosol during the period 2003-2007 relative to 1997-2002, consistent with an increase in dust activity. This accords with an independent finding of increasing aerosol loading over the Australian region as a whole, suggesting that rising dust activity over the Lake Eyre Basin may be a significant contributor to changes in the aerosol budget of the continent.
\end{abstract}

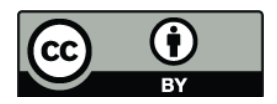

Correspondence to: R. M. Mitchell (Ross.Mitchell@csiro.au)

\section{Introduction}

Atmospheric particulates or aerosols influence climate both via direct interaction with the solar and terrestrial radiation fields, and indirectly through the modification of cloud microphysics, with effects on cloud reflectance and lifetimes (Forster et al., 2007). Hence, measuring and understanding changes in aerosol loading over time are essential to climate prediction. Wild et al. (2005) reported that the multi-decadal reduction in solar irradiance at the earth's surface known as global dimming had largely reversed over the Northern Hemisphere around 1990, probably due to reduction in pollution aerosol emissions and their effect on cloud properties; however continued dimming was noted over Asia due to growing aerosol emissions. Recently, Wang et al. (2009) inferred a significant increase in global aerosol loading over land during the period 1973-2007 from declining visibility measurements, including a substantial increase in implied aerosol loading over Australia in the period 2000-2007.

Potential climate effects of aerosol over the Australian region were recently reviewed by Rotstayn et al. (2009b). Although distant from most major aerosol sources in the Northern Hemisphere, Australian climate is subject to a number of known or suspected aerosol influences including increased rainfall in the north west due to modification of ocean heat transport caused by East Asian pollution aerosol (Rotstayn et al., 2007). Australia is a globally significant source of biomass burning aerosol, with about $10 \%$ of global emissions arising largely from seasonal savanna burning in the tropical north. While large radiative forcings have been demonstrated from this source (O'Brien and Mitchell, 2003; Luhar et al., 2008), its climate implications are yet to be understood.

Australia is the largest dust source in the Southern Hemisphere (Tanaka and Chiba, 2006; Li et al., 2008) with an emission rate of around $100 \mathrm{Tg} / \mathrm{yr}$ or $5 \%$ of the global total, although this value is very model-dependent, with estimates ranging from 2.5\% (Zender et al., 2003) to 15\% (Miller et al., 2004b). Recently, Rotstayn et al. (2009a) showed that inclusion of an interactive aerosol scheme in the CSIRO global

Published by Copernicus Publications on behalf of the European Geosciences Union. 
climate model greatly enhanced its capacity to represent Australian rainfall, particularly the increased variability of rainfall in the southeast. Furthermore, there was tentative evidence of a connection between increased rainfall variability and dust aerosol loading, suggesting that dust feedbacks may be important in understanding Australian climate.

With major dust sources in the Northern Hemisphere extending from Saharan Africa through the middle east to the Asian deserts, dust feedbacks on climate have received considerable attention. For example, Miller et al. (2004a) noted that increased dust load reduces turbulent momentum coupling through the planetary boundary layer, hence reducing surface wind and applying a negative feedback. Pérez et al. (2006) explored the potential for improved numerical weather prediction through realistic treatment of dust in a regional model, while Rodwell and Jung (2008) studied longrange propagation of dust feedbacks, demonstrating the potential for rainfall effects. The study by Heinold et al. (2008) underlined the complexity of this issue by pointing out the potential for both positive and negative dust feedbacks over strong source regions. Tegen et al. (2004) studied the balance between natural and anthropogenic dust sources, and found that future changes in atmospheric dust load are likely to be controlled by climate change induced effects rather than through human activities per se.

Understanding the climate impact of Australian dust aerosol requires better knowledge of the important sources and how these change over time. The primary dust source on the Australian continent is the Lake Eyre Basin (LEB), a drainage basin of roughly 1.2 million $\mathrm{km}^{2}$ contained within the much larger "arid zone" where the ratio of annual mean pan evaporation to median rainfall exceeds 30:1. The LEB comprises a complex mixture of saline lakes, claypans, dunefields and stony deserts or gibber. The saline lakes receive alluvial sediments from inland-flowing river systems, whose flow is highly intermittent; further details of the geomorphology and hydrology of the area can be found in Tyler et al. (1990). The complex relation between dust emission and geomorphology in this region was studied by Bullard et al. (2008). They found heterogeneous dust sources with significant contributions from sand dunes, floodplains and ephemeral lakes (particularly lake margins), overturning a perception that dry lake beds constitute the major source (Washington et al., 2003).

The climate impact of aerosol also depends on a knowledge of their optical properties. On this point, Qin and Mitchell (2009) showed that Australian continental aerosol occurs in four main groups, one of which they identified as mineral dust. In common with overseas dusts, Australian dust shows enhanced absorption in the blue spectral region due to the iron oxide hematite. There is evidence for higher hematite levels in dust from the LEB than usually found in Northern Hemisphere dusts, although the situation is complex as even within the LEB the dust properties are heterogeneous (Bullard and White, 2002).
This study investigates the time variation and climatology of aerosol loading over the Australian arid zone, through the analysis of a decadal time series of data from an aerosol ground station located within in the LEB.

\section{Observations}

The measurements reported here were obtained from the Aerosol Ground station operated by the Commonwealth Scientific and Industrial Research Organisation (CSIRO) at Tinga Tingana in the Strzelecki Desert of South Australia (latitude $28.98 \mathrm{~S}$, longitude $139.99 \mathrm{E}$ ). This site forms part of the CSIRO Aerosol Ground Station Network (AGSNet), affiliated with NASA's Aerosol Robotic Network (AERONET). The location of Tinga Tingana within the Lake Eyre Basin is shown in Fig. 1.

In common with all AERONET installations, the station supports a Cimel sun photometer, model CE318. In addition, the Tinga Tingana station also includes a model M903 Radiance Research nephelometer, and subsidiary environmental measuring instruments including a barometer, anemometer and wind vane. Because the location is remote, data communication takes place via a satellite telephone, with the entire system powered by solar panels. The satphone link provides two-way communications, allowing status monitoring, data download, and modification of operational parameters as required.

\subsection{CE318 sun photometer}

The operation and data quality of the CE318 sun photometers as deployed by AERONET has been described in detail by Holben et al. (1998). The performance of these instruments under conditions prevailing in the Australian outback was examined by Mitchell and Forgan (2003). The latter work showed that application of advanced calibration techniques to collocated sun photometers operated at sea level in central Australia yielded absolute accuracy of 0.007 in aerosol opti-

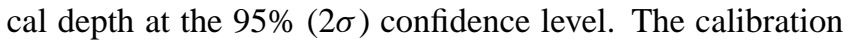
strategy in the present study was based on this methodology.

A sun photometer was first installed at Tinga Tingana in June 1997, and the data set reported here extends to the end of February 2007. Over this interval, the instrumentation was maintained by periodic site visits, which included cleaning and swapout of the sun photometer as required. For calibration purposes, the logarithmic exoatmospheric instrument response $\ln \mathrm{V}_{0}$ in each channel was assumed to vary linearly with time throughout each of 26 sub-intervals between maintenance visits. For each of these, the technique described by Mitchell and Forgan (2003) was applied, consisting of (a) identification of "Langley" periods of highly stable atmospheric transmission, allowing high-precision determination of $\ln \mathrm{V}_{0}$ at a reference wavelength, usually $870 \mathrm{~nm}$, and (b) iterative application of the general method (Forgan, 1994) with 


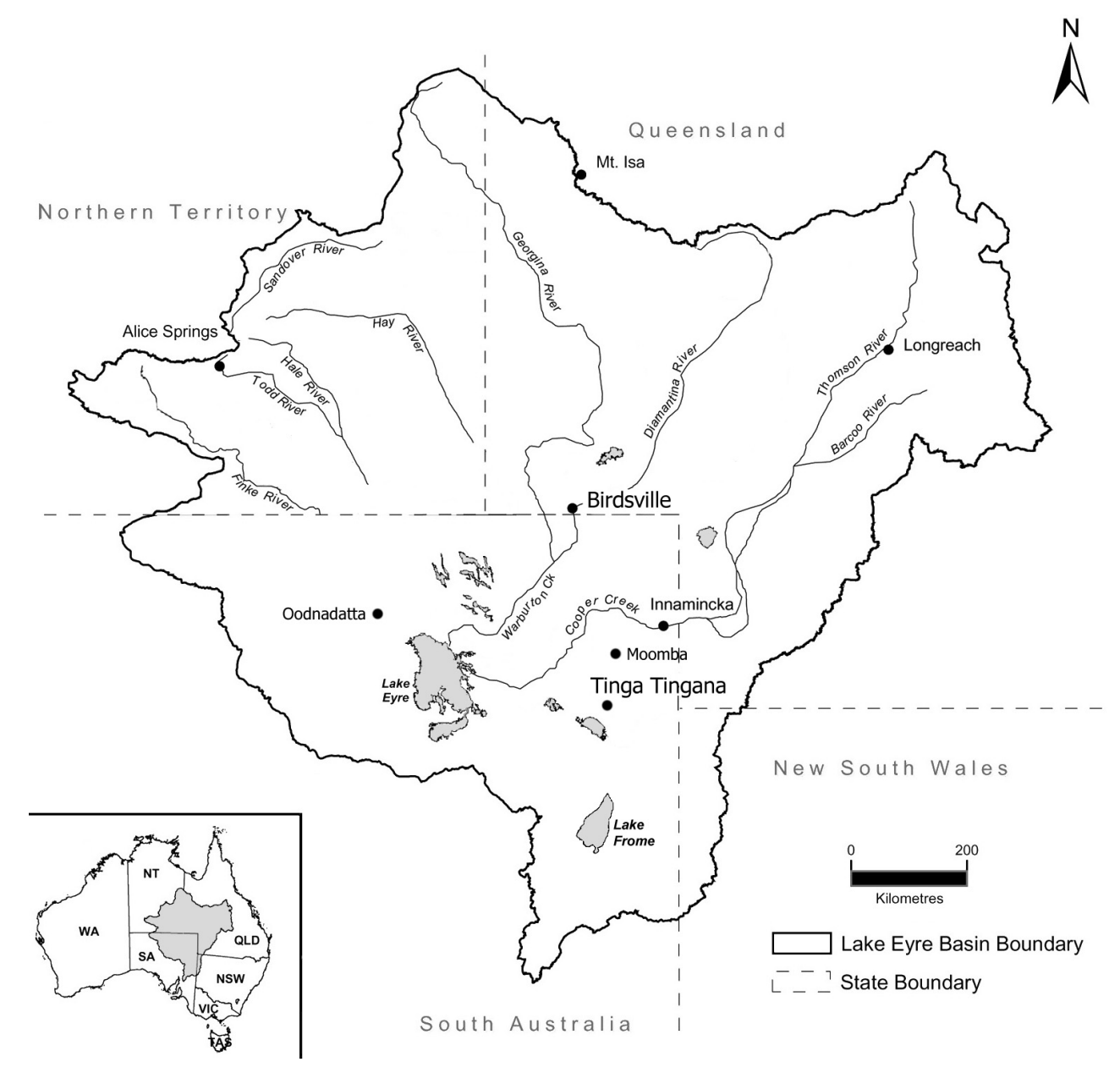

Fig. 1. Map showing the Lake Eyre Basin of central Australia. CSIRO Aerosol Ground Stations are located at Tinga Tingana and Birdsville.

successively shorter reference wavelengths. This approach assumes stability of the aerosol size distribution but, unlike the standard Langley method, not the aerosol optical depth. In effect it propagates a high precision estimate of $\ln \mathrm{V}_{0}$ obtained at $870 \mathrm{~nm}$ toward shorter wavelengths. Typically, the uncertainty in $\ln V_{0}$ at $440 \mathrm{~nm}$ obtained by this method is reduced by a factor of $\sim 2$ over that obtained from direct Langley analysis.

Cloud removal was performed by screening the data for temporal variations characteristic of clouds, following Smirnov et al. (2000). First, the data are filtered for shortterm variations by requiring that the coefficient of variation amongst multiple measurements acquired in a two-minute sliding window be $<1 \%$. Second, the coefficient of variation for all obervations during a given day is calculated. If this is $<1 \%$, no further tests are applied. If not, data points more than three standard deviations from the daily mean are eliminated. This latter step is useful in removing data affected by thin cirrus cloud, that may pass the high freqency flitering offered by the previous step.

\subsection{M903 Radiance Research Nephelometer}

Operation of the M903 nephelometer in the Australian Outback has been described in detail by Mitchell et al. (2009). In brief, the instrument reports the aerosol scattering coefficient at $530 \mathrm{~nm}$ of ambient air sampled at $2 \mathrm{~m}$ above the surface and passing through the instrument at a rate of $\sim 20 \mathrm{~L} \mathrm{~min}^{-1}$. Mitchell et al. (2009) found a detection limit of $\sim 0.2 \mathrm{Mm}^{-1}$ at the $95 \%$ confidence level for a 5-min averaging period. However, realistic uncertainties are much larger than this, due to the need to track drifts in instrument response over time. For the deployment discussed here, they calculated 95\% uncertainties in aerosol scattering coefficient of $\sim 15 \%$ at background levels $\left(\sim 10 \mathrm{Mm}^{-1}\right)$, falling to $\sim 5 \%$ for scattering coefficients $>100 \mathrm{Mm}^{-1}$. Mitchell et al. (2009) also examined the reduction in reported aerosol scattering coefficient caused by selective loss of large particles at the inlet, and undersampling of forward scattered radiance in the instrument (truncation error). For a particular dust aerosol derived from AERONET inversion of sky radiance data from 
Tinga Tingana, these effects combine to reduce the reported scattering coefficient by a factor of 2.0 under calm conditions, rising to 2.4 at a wind speed of $2 \mathrm{~m} \mathrm{~s}^{-1}$ due to the dependence of inlet efficiency on wind speed. The time series analysis presented in Sect. 3.1 below focuses on the relative change in scattering coefficient over the deployment interval, corrected for response drift but not inlet efficiency or truncation error. However, for calculation of visibility as considered in Sect. 3.3 it is necessary to consider the latter corrections.

\section{Results and discussion}

\subsection{Aerosol time series}

Figure 2 shows the time series of monthly mean aerosol properties at Tinga Tingana over the period 1997-2007, together with other variables. Data gaps appear as blank intervals between line segments. The top panel shows aerosol optical depth at $440 \mathrm{~nm}\left(\tau_{440}\right)$, with aerosol scattering coefficient at $530 \mathrm{~nm}\left(\sigma_{530}^{\text {sca }}\right)$ shown in the middle panel. The elevated aerosol optical depth during September 2000 resulted from an incursion of smoke-laden air from extensive fires in the Pilbara region of north-western Australia, unusual in both the vast quantity of smoke produced and its advection to the south. The lack of a corresponding response in the scattering coefficient identifies this as an elevated layer with little if any aerosol close to the surface.

A least-squares fit to the entire aerosol optical depth record indicates a trend of $0.0029 \mathrm{yr}^{-1}$ with a standard uncertainty of 0.0015 indicating that the trend is significant at the $95 \%$ confidence level. If the September 2000 datum is removed, the upward trend increases and is significant at the 99\% level. The enhancement of aerosol optical depth over the decade is substantial; if all data are considered, $\tau_{440}$ increased from 0.042 to 0.071 or $69 \%$, while if September 2000 is excluded, the fitted trend indicates a doubling from 0.036 to 0.071 .

Linear regression of the time series of scattering coefficient (middle panel) suggests a more marked increase in near-surface aerosol loading than in the column, with a trend of $1.27 \mathrm{Mm}^{-1} \mathrm{yr}^{-1}$, corresponding to a threefold increase in scattering coefficient over the study period. This trend is largely driven by an abrupt increase in the amplitude of the seasonal cycle beyond mid-2002. Before this time, the scattering coefficient shows an annual variation declining from $\sim 30 \mathrm{Mm}^{-1}$ in $1999-2000$ to $<10 \mathrm{Mm}^{-1}$ in $2001-2002$. The transition after mid-2002 shows the scattering coefficient increasing to its largest recorded monthly mean of $60 \mathrm{Mm}^{-1}$ in January 2003. Subsequently, the annual cycle remains well defined and peaks in January or December, with peak values in the range $25-50 \mathrm{Mm}^{-1}$.

Examination of the upper panels in Fig. 2 indicates higher aerosol loading during the austral spring and summer months with consistently low aerosol during autumn and winter. This is confirmed by a least-squares fit to the months May, June and July only. For the aerosol optical depth at $440 \mathrm{~nm}$, this yields a value of 0.028 with no significant trend at the $1 \sigma$ level. Likewise, a least-squares fit to the monthly mean scattering coefficient in May, June and July shows no significant trend. This suggests long-term stability in the winter time background aerosol loading, and that the explanation for the trend observed at other months must be due to changing seasonal dependence of aerosol sources affecting this region, rather than a general upscaling.

The lower panel of Fig. 2 shows the time variation of rainfall anomaly based on rainfall data from Moomba, located $100 \mathrm{~km}$ north of Tinga Tingana (see Fig. 1), and the El Niño-Southern Oscillation index Niño 3.4 SST based on sea surface temperature anomalies in the equatorial Pacific Ocean (Philander, 1990). Correlation between ENSO and Australian rainfall is well studied (Nicholls et al., 1996) although poorly understood; other ocean phenomena including the Indian Ocean Dipole are also under investigation (Ummenhofer et al., 2009). The rainfall record shows wet periods in 1998 and 2000, coinciding with La Niña events (negative ENSO index). The year 2002 saw 11 consecutive dry months accompanied by a moderate El Niño (positive ENSO index), which appeared to herald the general increase in seasonal intensity of the aerosol loading in subsequent years. However there is significant interannual variability that will be further discussed below.

\subsection{Increase in aerosol loading}

A number of authors have used visibility reports from meteorological stations to study change in aerosol loading, based on the reciprocal relation between local visual range (visibility) and aerosol extinction coefficient given by Koschmieder (1924). Mahowald et al. (2007) found evidence for changes in dust loading over some regions during the period 19742003, but no coherent global trend nor a significant change over the Australian region. Lamb et al. (2009) related contrasting periods of dust activity over Australia to changing climate modes in the Pacific Ocean and particularly their effect on surface winds. This analysis is consistent with the general reduction in dustiness from 1977 onward relative to the very active 1960s. Their visibility-based time series captures the 2002/3 dust peak discussed here, but not those of $2004 / 5$ and $2005 / 6$, a result at odds with the comparable method of Bullard et al. (2008) for 2004/5 further discussed in the following section.

Recently, Wang et al. (2009) used visibility measurements to infer a global increase in aerosol loading since the late 1970s, largely driven by Asia and South America, but with a significant increase over Australia since 1999. More detailed examination of the Australian time series (kindly provided in tabular form by the author) shows a positive trend between October 1999 and December 2005 of $\sim 0.0035 \mathrm{yr}^{-1}$, followed by a step of $\sim 0.03$, then a further increase at about 


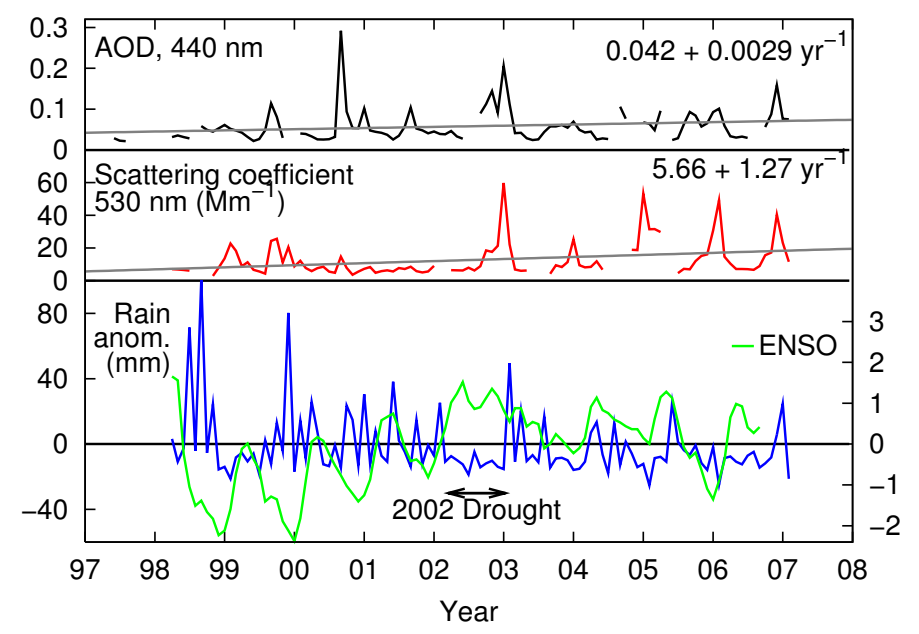

Fig. 2. Monthly mean time series obtained from the CSIRO aerosol ground station at Tinga Tingana from 1997 to 2007. The top panel shows aerosol optical depth at $440 \mathrm{~nm}$, the middle panel shows aerosol scattering coefficient at $530 \mathrm{~nm}$, while the lower panel shows rainfall anomaly and the ENSO index Niño 3.4 SST. The rainfall data were obtained from Moomba, approximately $100 \mathrm{~km}$ north of Tinga Tingana.

the previous rate until the end of the time series in 2007. In order to compare this result with the present data set, we fitted a linear trend line to the time series of $\tau_{440}$ between October 1999 and February 2007, excluding the smoke-affected datum of September 2000, yielding a trend of $0.0032 \mathrm{yr}^{-1}$. While the close agreement between this local measure and the regional estimate of Wang et al. (2009) may be fortuitous, it nevertheless leaves open the possibility that increased dust load over Tinga Tingana, and by extension, the LEB, may be representative of an aerosol increase on a continental scale.

\subsection{Relation to regional dust sources}

Bullard et al. (2008) identified the important geomorphological units involved in dust production in the LEB, through examination of dust plumes in MODIS imagery. The most important sources were found to be activated dunes, floodplains and ephemeral lakes and their margins. In addition, Hesse and Simpson (2006) investigated the relation between dune mobilisation and loss of vegetation and surface crust. The interpretation of changes in aerosol load measured at Tinga Tingana can be understood on the basis of these studies.

The location of Tinga Tingana in the Strzelecki dunefield close to the arid lake system to the south (Fig. 1) suggests that the dust burden is likely to be controlled by emission from dunes and ephemeral lakes and their margins. The period of low dust activity from 1997-2002 follows from the effect of rainfall during this period in supporting the growth of ephemeral dune vegetation and crust formation, suppressing dust emission while at the same time supplying alluvial fine material to lakes and run-on areas for later deflation. Measurements by Hesse and Simpson (2006) on dunes in the Strzelecki and Simpson deserts in July 2002 showed large depths of loose sand, with very low plant cover. This sampling occurred midway through the drought period seen in the lower panel of Fig. 2, so further activation of the dunes is likely leading up to the 2002/3 dust season. The combination of this extreme dune activation with large sediment supply to the nearby lakes explains the very high dust load measured during the 2002/3 dust season.

Widespread rainfall in 2003 caused re-establishment of ephemeral cover and surface crust, as reported by Hesse and Simpson (2006) from measurements obtained in September 2004. This is evident in the comparatively small dust season peak in 2003/4. In subsequent years the dust season intensity returned to high levels as seen by the scattering coefficient time series; this also suggests a modest decrease in peak intensity from $2004 / 5$ to $2006 / 7$, possibly related to the limited supply of erodible material given persistent drought conditions since the 2003 rains.

The relation between the dust activity observed at Tinga Tingana and that across the LEB is further examined in Fig. 3. This charts dust activity according to "dust storm year" (DSY), extending from July to the following June to avoid division of the summer dust maximum across different years. Figure 3 shows the number of days per dust storm year when the scattering coefficient entered the ranges 100$1000 \mathrm{Mm}^{-1}$ and $>1000 \mathrm{Mm}^{-1}$ at least once. Episodes in these ranges are labelled "signifcant" and "major", as they denote enhancements over the typical background scattering coefficient $\left(\sim 10 \mathrm{Mm}^{-1}\right)$ by factors of $10-100$ and $>100$ respectively. Also shown is the number of "dust storm days" (DSD) reported by Bullard et al. (2008), defined as the number of days on which the local visual range fell below $1 \mathrm{~km}$ at any of 19 meteorological stations in the LEB itself or at another station within $250 \mathrm{~km}$ of its boundary. The 


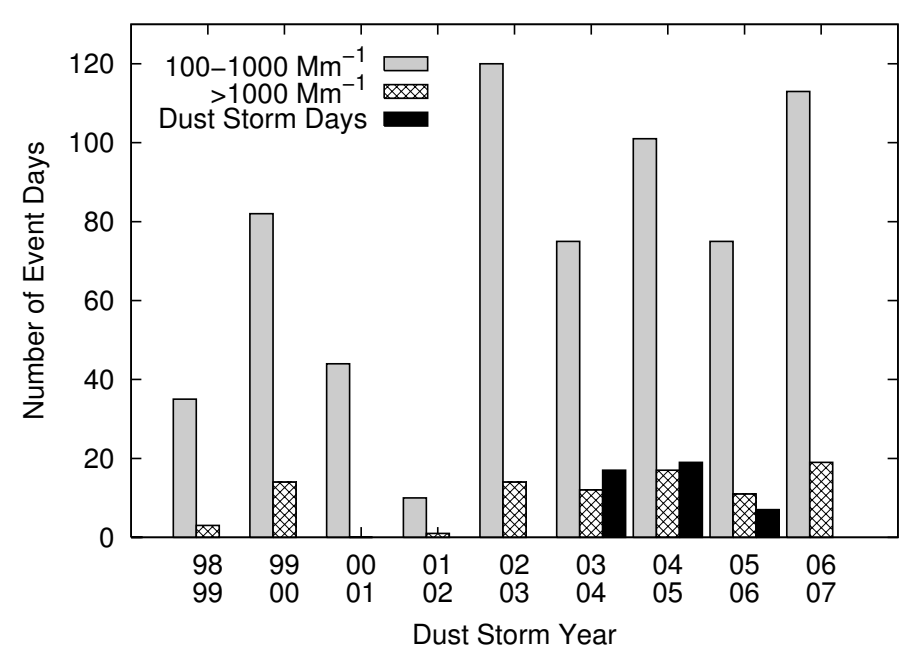

Fig. 3. Comparison of dust events at Tinga Tingana with the Dust Storm Day (DSD) count of Bullard et al. (2008) where available. The increased incidence in dust event days at Tinga Tingana from $2002 / 3$ on is clear at both the "significant" level $\left(100<\sigma<1000 \mathrm{Mm}^{-1}\right)$ and the "major" level $\left(\sigma>1000 \mathrm{Mm}^{-1}\right)$. Although the diagram suggests a correspondence between DSDs and "major" dust event days at Tinga Tingana, further analysis reveals that only a small number of the basin-wide DSDs are also seen at Tinga Tingana as "major" events. Equally, most major event days recorded at Tinga Tingana were not registered as DSDs. However, 50\% of DSDs were associated with "significant" dust activity at Tinga Tingana.

Table 1. Relation between basin-wide Dust Storm Days as reported by Bullard et al. (2008) and dust activity at Tinga Tingana. For each dust storm year (DSY) the table lists the number of dust storm days, the number of these on which scattering coefficient data were available at Tinga Tingana, then the number of these on which scattering coefficients in excess of $100 \mathrm{Mm}^{-1}$ and $1000 \mathrm{Mm}^{-1}$ respectively were recorded at least once. The column labelled "TT Total" lists the total number of days on which major dust events were recorded at Tinga Tingana, while the final column lists the number of major events at Tinga Tingana which were unrecorded in the DSD inventory of Bullard et al. (2008).

\begin{tabular}{|c|c|c|c|c|c|c|}
\hline \multirow[b]{2}{*}{ DSY } & \multirow[b]{2}{*}{ DSD } & \multicolumn{3}{|c|}{ Coincident events at TT } & \multirow{2}{*}{$\begin{array}{l}\text { TT Total } \\
\sigma>1000\end{array}$} & \multirow{2}{*}{$\begin{array}{l}\text { Unreported } \\
\text { major events }\end{array}$} \\
\hline & & Any $\sigma$ & $\sigma>100$ & $\sigma>1000$ & & \\
\hline 2003-2004 & 17 & 11 & 7 & 1 & 11 & 10 \\
\hline 2004-2005 & 19 & 13 & 10 & 2 & 15 & 13 \\
\hline 2005-2006 & 7 & 6 & 4 & 3 & 8 & 4 \\
\hline
\end{tabular}

aerosol scattering coefficient corresponding to $1 \mathrm{~km}$ visual range can be estimated from the Koschmieder (1924) relation, $V=3.9 / \sigma^{\text {ext }}$. Hence, for a dust single scattering albedo at $550 \mathrm{~nm}$ of $\sim 0.95$ (Qin and Mitchell, 2009), the scattering coefficient corresponding to a visual range of $1 \mathrm{~km}$ is $\sim 3700 \mathrm{Mm}^{-1}$. Applying a correction factor of 2.4 to relate reported to ambient scattering coefficient under windy conditions (see Sect. 2.2), the corresponding threshold in reported scattering coefficient is $\sim 1500 \mathrm{Mm}^{-1}$.

Figure 3 shows sustained enhancement for both "significant" and "major" event groups from DSY 2002/3 onwards. For the three years covered by Bullard et al. (2008), the number of dust storm days across the LEB is roughly commensurate with the number of major dust events at Tinga Tingana. Since the $1 \mathrm{~km}$ local visual range defining the dust storm days is commensurate with the scattering coefficient of $>1000 \mathrm{Mm}^{-1}$, it is tempting to infer that the nephelometer record at Tinga Tingana is representative of "basin-wide" dust activity.

However, attempts to match the specific set of dust storm days each year in the Bullard et al. (2008) data set with the events at Tinga Tingana reveal a different picture. In addition to the published tally of dust storm days, the authors kindly provided a list of dates on which the events occurred (Bullard 2009, personal communication). This list was examined for coincidences with the nephelometer record from Tinga Tingana. Table 1 shows that for the 17 DSDs reported in 2003/4, on 11 of which Tinga Tingana data were available, only 1 of these recorded a major event, although 7 recorded significant events. Similar results apply in the other two years, although the coincidence rate is improved in 2005/6 where 3 out of 6 matching days recorded major events. This result confirms 
that major dust outbreaks are sub-basin scale events, dependent on the detailed geomorphological factors discussed by Bullard et al. (2008) and Hesse and Simpson (2006). However, Table 1 also shows that around 50\% of DSDs coincide with $\sigma>100 \mathrm{Mm}^{-1}$ at Tinga Tingana, suggesting basin-scale dust mobilisation at lower but still significant levels.

As noted by Bullard et al. (2008), the sparsity of meteorological stations across the LEB means that many dust events go unrecorded by human observers. Another factor concerns the problem of recording nocturnal events, where usually no observer is on duty and no visibility estimate is possible. To complicate matters further, there is a nocturnal bias in the timing of major dust events at Tinga Tingana from 2002/3 onward, with $75 \%$ of records with $\sigma>1000 \mathrm{Mm}^{-1}$ occurring between 1800 and 0600 local time. In contrast, events in the range $100-1000 \mathrm{Mm}^{-1}$ were unbiased (49\% nocturnal).

The right-hand column of Table 1 highlights the extent of these issues by listing the number of major events at Tinga Tingana in each dust storm year that were unreported in the tally of DSDs. These range from $\sim 90 \%$ in $2003 / 4$ and $2004 / 5$ to $50 \%$ in $2005 / 6$, once again emphasising the importance of sub-basin scale dust activity. This issue is being addressed by engaging members of the outback community in recording dust activity as part of the DustWatch initiative (Leys et al., 2008), and by re-analysis of visibility reports from meteorological station records (O'Loingsigh et al., 2010).

\subsection{Interrelation between aerosol optical depth and scattering coefficient}

As noted above, previous studies have attempted to infer column aerosol loading from surface visibility estimates (Mahowald et al., 2007; Wang et al., 2009). Since visibility is inversly related to the aerosol scattering coefficient, the present data set allows direct assessment of this approach. For an unbiased comparison between daily mean aerosol optical depth and scattering coefficient, it is necessary to exclude nighttime nephelometer data, when the sun photometer is inactive. Day-time means of the nephelometer data were obtained by averaging the scattering coefficient over the hours 0600-1800 each day. Spectral interpolation was applied to obtain the aerosol optical depth at $530 \mathrm{~nm}$, based on the values at 440 and $670 \mathrm{~nm}$ assuming an Ångström-like variation between them. The reported scattering coefficient was corrected for calibration drift, truncation error and inlet efficiency assuming calm conditions following Mitchell et al. (2009).

The scatterplot of $\tau^{\text {sca }}$ against $\sigma^{\text {sca }}$ is shown in Fig. 4. The linear correlation coefficient of $R^{2}=0.24$ indicates a weak relation between near-surface and column aerosol. The majority of data are bounded by the region $\left(0<\sigma^{\text {sca }}<50 \mathrm{Mm}^{-1}\right)$, and $\left(0<\tau^{\text {sca }}<0.15\right)$. Points outside this region show a slight bias toward cases of high optical depth and low scattering coefficient, indicative of lofted aerosol. The opposite case, with high levels of surface aerosol tailing off rapidly with height, occurs less frequently but is still significant.

The ratio of aerosol optical depth to scattering coefficient gives the scale height of the aerosol vertical distribution, which has not previously been characterised over the Australian arid zone. Earlier studies focused on the near-surface vertical dust profiles (e.g., Butler et al. (2005), 0-10 m; McGowan and Clark (2008), 0-500 m), not sufficiently high to characterise the aerosol scale height.

The extinction optical depth is defined as the vertical integral of the extinction coefficient, $\sigma^{\text {ext }}$. Since the scattering coefficient is given by $\sigma^{\text {sca }}=\varpi \sigma^{\text {ext }}$ where $\varpi$ is the single scattering albedo, the extinction optical depth and scattering coefficient are related as

$\tau^{\mathrm{ext}}=\int_{0}^{\infty} \frac{\sigma^{\mathrm{sca}}(z)}{\varpi(z)} d z$.

For a well-mixed layer with constant $\sigma^{\text {sca }}$ up to height $h$ and zero beyond, the vertical integration yields $\tau^{\mathrm{ext}}=h \sigma^{\text {sca }} / \varpi$, assuming the single scattering albedo is independent of height. Hence the scale height $h$ can be derived from the ratio $\varpi \tau^{\text {ext }} / \sigma^{\text {sca }}$. The same result is obtained for the well-studied exponential distribution $\sigma^{\text {sca }}(z)=\sigma^{\text {sca }}(0) \exp ^{-z / h}$.

The frequency distribution of the scale height $h=$ $\varpi \tau^{\text {ext }} / \sigma^{\text {sca }}$ over the 10 -year study period is shown in Fig. 5. The single scattering albedo $\varpi$ was assumed to be 0.95 following Qin and Mitchell (2009). The overall distribution peaks at $\sim 2.5 \mathrm{~km}$, with broad shoulders, particularly towards large scale heights. During the quiescent months May-July, the mode scale height is reduced to $\sim 2 \mathrm{~km}$, as expected in view of a shallower mixed layer and low incidence of lofted aerosol in the winter season. The period August-November is characterised by larger scale heights, peaking at $5 \mathrm{~km}$, and giving evidence for lofted aerosol, with a prominent shoulder between $6.5-8 \mathrm{~km}$ caused by elevated layers such as the significant smoke incursion of September 2000. The period December-April covers the summer dust maximum, and shows a broad peak between $2-5 \mathrm{~km}$ indicating a deeper mixed layer during this season.

These findings amply demonstrate the difficulty of attempting to infer column aerosol loading from surface measures such as visibility. They also provide a data set of potential value for validating aerosol transport models over the Australian arid zone.

\subsection{Aerosol climatology}

Figure 6 displays the annual cycles of aerosol optical depth, scattering coefficient and Ångström exponent derived from a decade of measurements at Tinga Tingana. The plot shows monthly means and standard deviations over the decade, and means for the two pentads 1997-2002 and 2003-2007.

The annual cycle of aerosol optical depth is bimodal with peaks in September and January. The September peak is enhanced by the unusually intense smoke plume of year 2000 , 


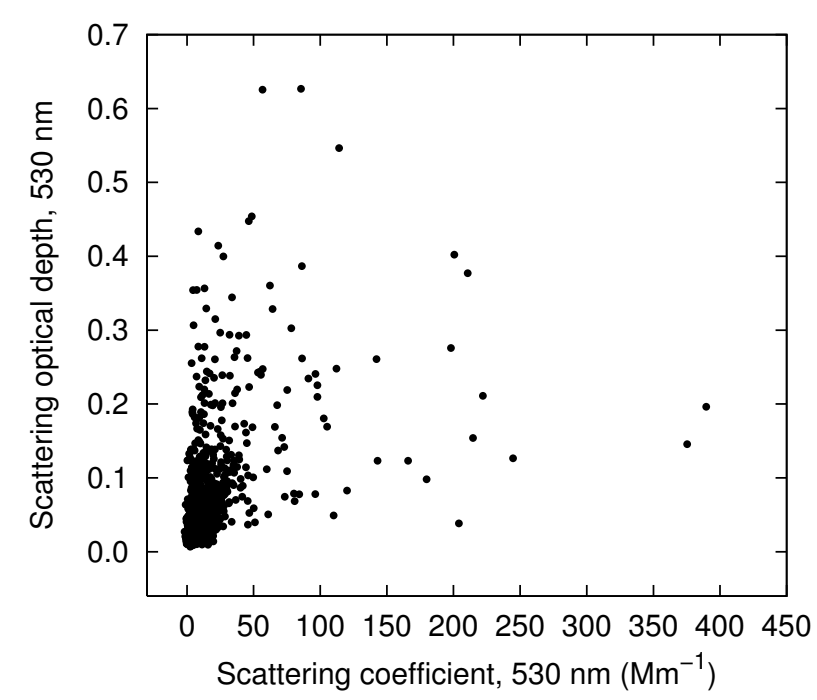

Fig. 4. Scatterplot of aerosol scattering optical depth against aerosol scattering coefficient, both at $530 \mathrm{~nm}$. The optical depths are daily means, while the corresponding scattering coefficients were obtained by averaging the nephelometer signal over daylight hours. The coefficient of correlation between the two variables is $R^{2}=0.24$.

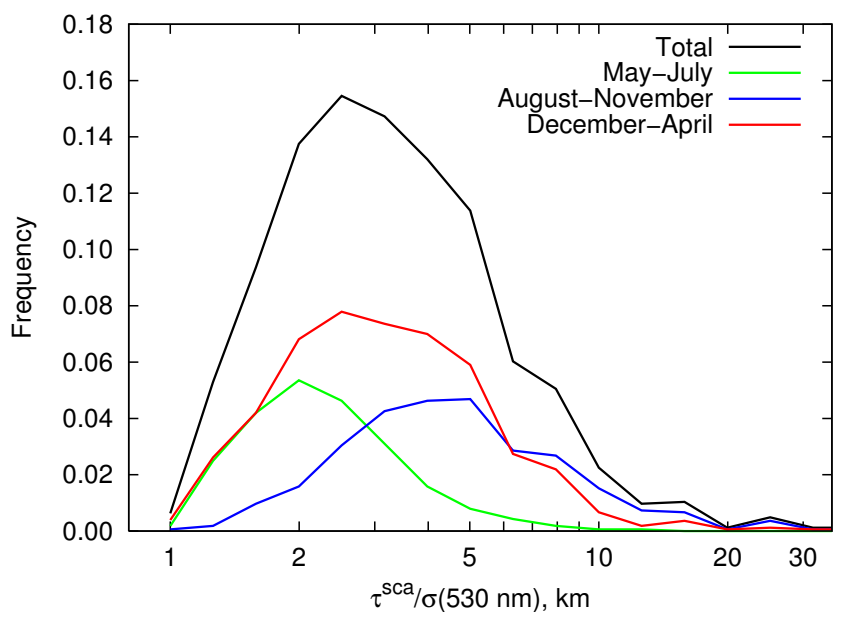

Fig. 5. Frequency distribution of the ratio of scattering aerosol optical depth to aerosol scattering coefficient at $530 \mathrm{~nm}$ over the 10 -year study period. This ratio is equivalent to the aerosol scale height. The separate distributions for three parts of the year reflect changes either in mixed-layer depth or the balance between lofted and surface material.

although it is still evident following removal of this datum. The plot suggests a post-2002 enhancement of $\sim 0.04$ between November and February.

The annual cycle of scattering coefficient (centre panel) shows a single maximum in January that is heavily influenced by the post-2002 period; no clear cycle is evident in the pre-2002 period. The lack of a September peak in the near-surface aerosol identifies the corresponding peak in the aerosol optical depth as being due to lofted material, while the strong January feature post-2002 is more closely related to surface aerosol.
The annual cycle of Ångström exponent shown in the lower panel confirms that the September peak is associated with fine particles, and is thus consistent with an influence from smoke aerosol, although a contribution from other fine aerosol including dust cannot be ruled out. The reduction in Ångström exponent through late spring to a weak minimum in January is consistent with increasing coarse mode aerosol as dust activity intensifies. The slightly lower values during the post-2002 period are consistent with a general increase in particle size, as expected from the greater incidence of significant and major dust events capable of entraining larger particles following the onset of the 2002 drought (see Fig. 3). 


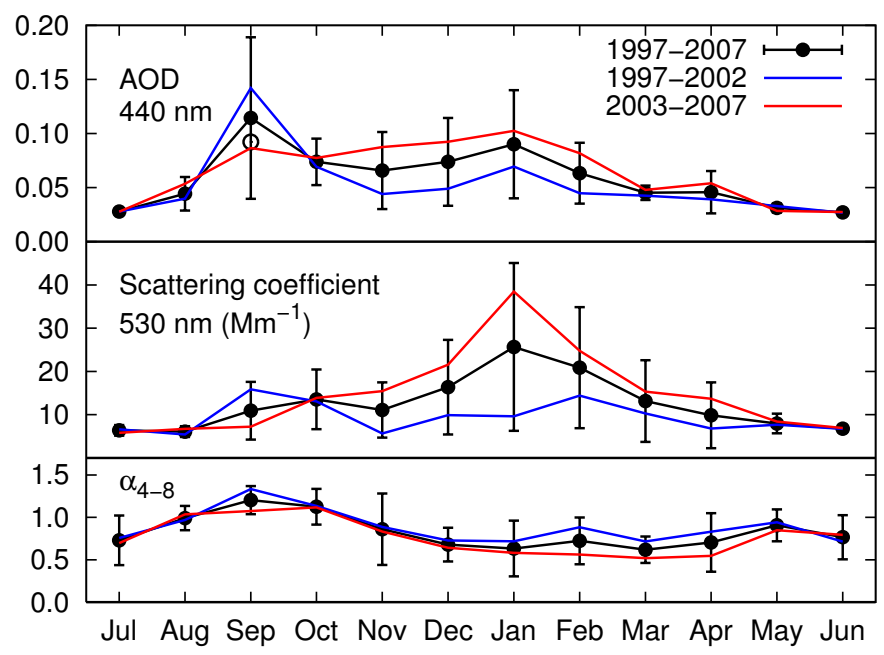

Fig. 6. Annual cycle of aerosol optical depth at $440 \mathrm{~nm}$, scattering coefficient at $530 \mathrm{~nm}$ and Ångström exponent (defined on the wavelength pair 440-870 nm) recorded at Tinga Tingana from 1997 to 2007. The vertical bars correspond to one standard deviation. The open circle is the mean aerosol optical depth for September, excluding the datum for September 2000 which was unusual in being grossly enhanced by smoke aerosol advected from fires in north-western Australia. The blue line shows the annual cycle from 1997-2002, while the red line is for 2003-2007.

Table 2. Climatology of aerosol optical depth and scattering coefficient at Tinga Tingana compiled over the decade 1997-2007. The aerosol optical depth is given at the four wavelengths common to all sun photometer filter configurations over that period. The rightmost columns list the aerosol scattering coefficient at $530 \mathrm{~nm}$ obtained from an integrating nephelometer.

\begin{tabular}{lcccccccccc}
\hline & \multicolumn{1}{c}{ 440 nm } & \multicolumn{4}{c}{ Aerosol Optical Depth } & \multicolumn{4}{c}{ Scat. Coef. } \\
Month & mean & sd & mean & sd & \multicolumn{2}{c}{$870 \mathrm{~nm}$} & \multicolumn{2}{c}{$1020 \mathrm{~nm}$} & \multicolumn{2}{c}{$530 \mathrm{~nm}, \mathrm{Mm}^{-1}$} \\
& & & & sd & mean & sd & & & mean & sd \\
\hline 1 & 0.090 & 0.050 & 0.064 & 0.034 & 0.059 & 0.031 & 0.064 & 0.033 & 25.7 & 19.4 \\
2 & 0.063 & 0.028 & 0.046 & 0.026 & 0.043 & 0.026 & 0.049 & 0.031 & 20.9 & 14.0 \\
3 & 0.045 & 0.007 & 0.033 & 0.007 & 0.031 & 0.008 & 0.035 & 0.009 & 13.2 & 9.4 \\
4 & 0.046 & 0.020 & 0.034 & 0.020 & 0.032 & 0.021 & 0.036 & 0.022 & 9.9 & 7.6 \\
5 & 0.031 & 0.004 & 0.020 & 0.003 & 0.017 & 0.002 & 0.020 & 0.003 & 8.0 & 2.3 \\
6 & 0.027 & 0.003 & 0.018 & 0.004 & 0.017 & 0.003 & 0.020 & 0.003 & 6.8 & 0.9 \\
7 & 0.028 & 0.003 & 0.019 & 0.003 & 0.018 & 0.003 & 0.020 & 0.003 & 6.4 & 1.2 \\
8 & 0.044 & 0.015 & 0.027 & 0.008 & 0.022 & 0.006 & 0.023 & 0.006 & 6.1 & 1.2 \\
9 & 0.114 & 0.075 & 0.063 & 0.040 & 0.048 & 0.027 & 0.044 & 0.022 & 10.9 & 6.7 \\
10 & 0.074 & 0.021 & 0.043 & 0.012 & 0.035 & 0.010 & 0.034 & 0.009 & 13.5 & 6.9 \\
11 & 0.066 & 0.036 & 0.042 & 0.022 & 0.038 & 0.020 & 0.039 & 0.018 & 11.1 & 6.4 \\
12 & 0.074 & 0.041 & 0.053 & 0.027 & 0.048 & 0.023 & 0.049 & 0.020 & 16.4 & 10.9 \\
\hline
\end{tabular}

A summary of the multi-spectral monthly aerosol climatology at Tinga Tingana is given in Table 2. These data indicate a well-defined aerosol baseline during the non-episodic months of May, June and July, that remained essentially unchanged over the decade of the observations. The mean and standard deviation of the aerosol optical depth during these months was $0.029 \pm 0.002$ at $440 \mathrm{~nm}$ while the corresponding scattering coefficient was $7.1 \pm 1.7 \mathrm{Mm}^{-1}$.

\section{Conclusions}

Observations at a site in the Australian Outback reveal significant changes in aerosol loading over the decade 19972007. Measurement of both the aerosol optical depth from a sun photometer and the scattering coefficient using a nephelometer allows analysis of the balance between columnintegrated and near-surface aerosol. Linear regressions suggest approximate doubling of the aerosol optical depth over the study period, with an even larger enhancement in the aerosol scattering coefficient driven by a persistent increase 
in the amplitude of the summer dust maximum following the onset of the 2002 drought.

Comparison of changes in aerosol optical depth and scattering coefficient reveal an intensification of near-surface aerosol activity in the years 2002-2007 relative to the preceding pentad. For both instruments, the changes are confined to the months other than May, June and July, during which no significant trend was observed.

Interannual differences in the intensity of dust seasons during the study period confirm the importance of sub-basin scale processes previously identified including activation of dunes via the removal of vegetation and surface crusts, and alluvial supply of erodible material to floodplains and dry lakes. Major dust events with local visual ranges below $1 \mathrm{~km}$ are usually associated with sub-basin scale deflation. However, occurrence of a major dust event anywhere in the basin appears as a "significant" dust event in the Tinga Tingana record about $50 \%$ of the time, suggesting a substantial level of basin-wide dust activity.

The daily mean aerosol optical depth is weakly correlated with the scattering coefficient, confirming the difficulty of using visibility estimates as a proxy for column aerosol. The aerosol scale height derived from the ratio of aerosol optical depth to scattering coefficient shows mode values typically between $2-3 \mathrm{~km}$, with significant broadening due to seasonal changes in the aerosol vertical distribution.

Examination of the decadal aerosol climatology at Tinga Tingana shows a bimodal annual cycle of aerosol optical depth, controlled by coarse-mode dust activity in January, and fine-mode lofted material in September, most likely due to smoke aerosol from long-range transport. The low and stable aerosol levels during the quiescent months of May, June and July set a baseline for Australian arid zone aerosol optical depth of $0.029 \pm 0.002$ at $440 \mathrm{~nm}$, with the corresponding scattering coefficient at $530 \mathrm{~nm}$ of $7.1 \pm 1.7 \mathrm{Mm}^{-1}$.

Finally, the increasing trend in aerosol load over the dust source region measured here is aligned with an independent estimate for the entire Australian region, suggesting that increasing dust load may be a significant component of aerosol change on a continental scale.

Acknowledgements. The authors wish to thank J. Bullard, C. Wang and coauthors for providing tabulated data from their respective publications. Valued field work assistance and discussions were provided by R. D. Graetz and D. M. O'Brien, and technical support by B. Petraitis and I. Morrissey. L. Rotstayn and T. O'Loingsigh contributed helpful comments on the manuscript. The authors acknowledge financial support from the following agencies: the Australian Department of Climate Change through the Australian Climate Change Science Program; the Office of Biological and Environmental Research of the US Department of Energy under contract 23662-001-01 3T as part of the Atmospheric Radiation Measurement program; and Australian Research Council grant DP0451400.

Edited by: A. Petzold

\section{References}

Bullard, J., Baddock, M., McTainsh, G. H. and Leys, J. F.: Subbasin scale dust source geomorphology detected using MODIS, Geophys. Res. Lett., 35, L15404, doi:10.1029/2008GL033928, 2008.

Bullard, J. E. and White, K.: Quantifying iron oxide coatings on dune sands using spectrometric measurements: An example from the Simpson-Strzelecki Desert, Australia, J. Geophys. Res., 107(B6), 2125 doi:10.1029/2001JB000454, 2002.

Butler, H., McTainsh, G., Hogarth, W., and Leys, J.: Kinky profiles: Effects of Soil Surface Heating upon vertical dust concentration profiles in the channel country of western Queensland, Australia, J. Geophys. Res., 110, F04025, doi:10.1029/2004JF000272, 2005.

Forgan, B. W.: General method for calibrating sun photometers, Appl. Opt., 33, 4841-4850, 1994.

Forster, P., Ramaswamy, V., Artaxo, P., Berntsen, T., Betts, R., Fahey, D., Haywood, J., Lean, J., Lowe, D., Myhre, G., Nganga, J., Prinn, R., Raga, G., Schulz, M., and Dorland, R. V.: Changes in atmospheric constituents and in radiative forcing, in: Climate Change 2007: The Physical Science Basis. Contribution of Working Group I to the Fourth Assessment Report of the Intergovernmental Panel on Climate Change, edited by: Solomon, S., Qin, D., Manning, M., Chen, Z., Marquis, M., Averyt, K. B., Tignor, M., and Miller, H. L.: Cambridge University Press, Cambridge, UK and New York, NY, USA, 153-180, 2007.

Heinold, B., Tegen, I., Schepanski, K., and Hellmuth, O.: Dust radiative feedback on Saharan boundary layer dynamics and dust mobilization, Geophys. Res. Lett., 35, L20817, doi:10.1029/2008GL035319, 2008.

Hesse, P. P. and Simpson, R. L.: Variable vegetation cover and episodic sand movement on longitudinal desert sand dunes, Geomorphology, 81, 276-291, doi:10.1016/j.geomorph.2006.04.012, 2006.

Holben, B. N., Eck, T. F., Slutsker, I., Tanré, D., Buis, J. P., Setzer, A., Vermote, E., Reagan, J. A., Kaufman, Y. J., Nakajima, T., Lavenu, F., Jankowiak, I., and Smirnov, A.: AERONET - A federated instrument network and data archive for aerosol characterization, Remote Sens. Env., 66, 1-16, 1998.

Koschmieder, H.: Theorie der horizontalen Sichtweite, Contrib. Atmos. Phys., 43, 33-55, 1924.

Lamb, P., Leslie, L., Timmer, R., and Speer, M.: Multidecadal variability of Eastern Australian dust and Northern New Zealand sunshine: Associations with Pacific climate system, J. Geophys. Res., 114, D09106, doi:10.1029/2008JD011184, 2009.

Leys, J., McTainsh, G., Strong, C., Heidenreich, S., and Biseaga, K.: DustWatch: Community networks to improve wind erosion monitoring in Australia, Earth Surf. Proc. Landforms, 33, 19121926, 2008.

Li, F., Ginoux, P., and Ramaswamy, V.: Distribution, transport, and deposition of mineral dust in the Southern Ocean and Antarctica: Contribution of major sources, J. Geophys. Res., 113, D10207, doi:10.1029/2007JD009190, 2008.

Luhar, A. K., Mitchell, R. M., Meyer, C. P. M., Qin, Y., Campbell, S. K., Gras, J. L., and Parry, D.: Biomass burning emissions over northern Australia constrained by aerosol measurements: II - model validation, and impacts on air quality and radiative forcing, Atmos. Environ., 42, 1647-1664, 2008. 
Mahowald, N. M., Ballantine, J. A., Feddema, J., and Ramankutty, N.: Global trends in visibility: implications for dust sources, Atmos. Chem. Phys., 7, 3309-3339, 2007, http://www.atmos-chem-phys.net/7/3309/2007/.

McGowan, H. A. and Clark, A.: A vertical profile of PM10 dust concentrations measured during a regional dust event identified by MODIS Terra, western Queensland, Australia, J. Geophys. Res., 113, F02S03, doi:10.1029/2007JF000765, 2008.

Miller, R. L., Perlwitz, J., and Tegen, I.: Feedback upon dust emission by dust radiative forcing through the planetary boundary layer, J. Geophys. Res., 109, D24209, doi:10.1029/2004JD004912, 2004a.

Miller, R. L., Tegen, I., and Perlwitz, J.: Surface radiative forcing by soil dust aerosols and the hydrologic cycle, J. Geophys. Res., 109, D04203, doi:10.1029/2003JD004085, 2004b.

Mitchell, R. M. and Forgan, B. W.: Aerosol measurements in the Australian Outback: intercomparison of sun photometers, J. Atmos. Oceanic Technol., 20, 54-66, doi:10.1175/15200426(2003), 2003.

Mitchell, R. M., Campbell, S. K., Qin, Y., and Gras, J.: Performance characteristics of integrating nephelometers in the Australian Outback, J. Atmos. Oceanic Technol., 26, 984-995, doi:1175/2008JTECHA1187.1, 2009.

Nicholls, N., Lavery, B., Frederiksen, C., and Drosdowsky, W.: Recent apparent changes in relationship between the El NiñoSouthern Oscillation and Australian rainfall and temperature, Geophys. Res. Lett., 23, 3357-3360, 1996.

O'Brien, D. M. and Mitchell, R. M.: Atmospheric heating due to carbonaceous aerosol in northern Australia - confidence limits based on TOMS aerosol index and sun-photometer data, Atmos. Res., 66, 21-41, doi:10.1016/S0169-8095(02)00173-4, 2003.

O’Loingsigh, T., McTainsh, G., Tapper, N., and Shrinkfield, P.: Lost in Code: A critical analysis of using meteorological data for wind erosion monitoring, J. Aeolian Res., submitted, 2010.

Pérez, C., Nickovic, S., Pejanovic, G., Baldasano, J. M., and Özsoy, E.: Interactive dust-radiation modeling: A step to improve weather forecasts, J. Geophys. Res., 111, D16206, doi:10.1029/2005JD006717, 2006.

Philander, S.: El Niño, La Niña, and the Southern Oscillation, Int. Geophys. Ser., 46, Elsevier, New York, USA, 223 pp., 1990.

Qin, Y. and Mitchell, R. M.: Characterisation of episodic aerosol types over the Australian continent, Atmos. Chem. Phys., 9, 1943-1956, 2009,

http://www.atmos-chem-phys.net/9/1943/2009/.

Rodwell, M. J. and Jung, T.: Understanding the local and global impacts of model physics changes: An aerosol example, Q. J. R. Meteorol. Soc., V134(635), 1479-1497, doi:10.1002/qj.298, 2008.
Rotstayn, L., Cai, W., Dix, M., Farquhar, G., Feng, Y., Ginoux, P., Herzog, M., Ito, A., Penner, J., Roderick, M., and Wang, M.: Have Australian rainfall and cloudiness increased due to the remote effects of Asian anthropogenic aerosols?, J. Geophys. Res., 112, D09202, doi:10.1029/2006JD007712, 2007.

Rotstayn, L. D., Collier, M. A., Dix, M. R., Feng, Y., Gordon, H. B., O'Farrell, S. P., Smith, I. N., and Syktus, J.: Improved simulation of Australian climate and ENSO-related climate variability in a GCM with an interactive aerosol treatment. Int J. Climatol., doi:10.1002/joc.1952, 2009a.

Rotstayn, L. D., Forgan, B. W., Gabric, A. J., Galbally, I. E., Gras, J. L., Keywood, M. D., Luhar, A. K., Mitchell, R. M., and Young, S. A.: Possible impacts of anthropogenic and natural aerosols on Australian climate and weather: a review, Int. J. Climatol., 29, 461-479, http://www.interscience.wiley. com, doi:10.1002/joc.1729, 2009b.

Smirnov, A., Holben, B. N., Eck, T. F., Dubovik, O., and Slutsker, I.: Cloud-screening and quality control algorithms for the AERONET database, Remote Sens. Environ., 73, 337-349, doi:10.1016/S0034-4257(00)00109-7, 2000.

Tanaka, T. Y. and Chiba, M.: A numerical study of the contributions of dust source regions to the global dust budget, Glob. Plan. Change, 52, 88-104, 2006.

Tegen, I., Werner, M., Harrison, S. P., and Kohfeld, K. E.: Relative importance of climate and land use in determining present and future global soil dust emission, Geophys. Res. Lett., 31, L05105, doi:10.1029/2003GL019216, 2004.

Tyler, M. J., Twidale, C. R., Davies, M., and Wells, C. B.: Natural History of the North East Deserts, ISBN 0-9596627-5-8, Royal Society of South Australia Inc., 1990.

Ummenhofer, C. C., England, M. H., McIntosh, P. C., Meyers, G. A., Pook, M. J., Risbey, J. S., Gupta, A. S., and Taschetto, A. S.: What causes southeast Australia's worst droughts?, Geophys. Res. Lett., 36, L04706, doi:10.1029/2008GL036801, 2009.

Wang, K., Dickinson, R. E., and Liang, S.: Clear sky visibility has decreased over land globally from 1973 to 2007, Science, 323, 1468-1470, doi:10.1126/science.1167549, 2009.

Washington, R., Todd, M., Middleton, N. J., and Goudie, A. S.: Dust storm source areas determined by the Total Ozone Monitoring Spectrometer and surface observations, Ann. Ass. Am. Geogr., 93, 297-313, 2003.

Wild, M., Gilgen, H., Roesch, A., Ohmura, A., Long, C. N., Dutton, E. G., Forgan, B. W., Kallis, A., Russak, V., and Tsvetkov, A.: From dimming to brightening: Decadal changes in solar radiation at Earth's Surface, Science, 308, 847-850, 2005.

Zender, C. S., Bian, H., and Newman, D.: Mineral Dust Entrainment and Deposition (DEAD) model: Description and 1990s dust climatology, J. Geophys. Res., 108(D14), 4416, doi:10.1029/2002JD002775, 2003. 